\title{
PENGARUH WAKTU OZONISASI TERHADAP PENURUNAN KADAR BOD, COD, TSS DAN FOSFAT PADA LIMBAH CAIR RUMAH SAKIT
}

\author{
Isyuniarto, Andrianto \\ PTAPB - BATAN Yogyakarta
}

\begin{abstract}
ABSTRAK
PENGARUH WAKTU OZONISASI TERHADAP PENURUNAN KADAR BOD, COD, TSS DAN FOSFAT PADA LIMBAH CAIR RUMAH SAKIT. Telah dilakukan penelitian pengaruh waktu ozonisasi terhadap penurunan kadar $B O D$, COD, TSS dan fosfat pada limbah cair rumah sakit. Tujuan penelitian adalah mempelajari pengaruh penambahan kapur dan pemakaian oksidan ozon untuk menurunkan kadar BOD, COD, TSS dan fosfat pada limbah rumah sakit. Penambahan kapur dimaksudkan untuk menambah jumlah ion $\mathrm{OH}$ sedangkan parameter waktu ozonisasi dimaksudkan untuk menyempurnakan oksidasi senyawa-senyawa organik dalam limbah dan pembentukan flok-flok. Dari penelitian yang dilakukan diperoleh hasil bahwa penambahan kapur yang optimum adalah 1,1\% (berat) dan waktu ozonisasi 20 menit. Pada kondisi ini diperoleh kadar BOD = 18,88 mg/l; COD = $25,68 \mathrm{mg} / \mathrm{l}, \mathrm{TSS}=80 \mathrm{mg} / \mathrm{l}$ dan fosfat $=1,52 \mathrm{mg} / \mathrm{l}$. Kondisi tersebut sudah memenuhi standar baku mutu yang ditetapkan, yaitu untuk $B O D=75 \mathrm{mg} / \mathrm{l} ; \mathrm{COD}=100 \mathrm{mg} / \mathrm{l}, \mathrm{TSS}=100 \mathrm{mg} / \mathrm{l}$ dan fosfat $=2,0 \mathrm{mg} / \mathrm{l}$.
\end{abstract}

Kata kunci : $B O D, C O D$, TSS, fosfat, ozon, kapur.

\section{ABSTRACT}

THE INFLUENCE OF OZONATED TIME ON THE DEGREE OF DEPRECIATION OF BOD, COD, TSS AND PHOSPHATE IN HOSPITAL LIQUID WASTE. The influence of ozonated time towards degree depreciation of BOD, COD, TSS and phosphate in hospital liquid waste was done. This research aim study influence of lime adding and ozone using to reduce of BOD, COD, TSS and phosphate in hospital waste. Added of lime mean for total increase ion $\mathrm{OH}$, while parameter of ozonation time mean to complete organic compounds oxidation in waste and flock formation. From this research it was found that optimum lime addition was 1.1\% (\% weight) and ozonation time was 20 minutes. In this condition it was achieved degree of BOD = $18.88 \mathrm{mg} / \mathrm{l} ; \mathrm{COD}=25.68 \mathrm{mg} / \mathrm{l}, \mathrm{TSS}=80 \mathrm{mg} / \mathrm{l}$ and phosphate $=1.52 \mathrm{mg} / \mathrm{l}$. This condition fulfil quality standard decided, that has to $B O D=75 \mathrm{mg} / \mathrm{l} ; \mathrm{COD}=100 \mathrm{mg} / \mathrm{l}$, TSS $=100 \mathrm{mg} / \mathrm{l}$ and phosphate $=2.0 \mathrm{mg} / \mathrm{l}$.

Key word: BOD, COD, TSS, phosphate, ozone, lime.

\section{PENDAHULUAN}

Dumah sakit merupakan institusi pelayanan kesehatan dengan inti kegiatan pelayanan preventif, kuratif, rehabilitatif dan promotif. Kegiatan tersebut akan menimbulkan dampak positif dan negatif. Dampak positif adalah peningkatan derajat kesehatan masyarakat, sedangkan dampak negatifnya antara lain adalah adanya limbah medis maupun nonmedis yang dapat menimbulkan penyakit dan pencemaran yang memerlukan perhatian khusus.

Selain itu, karena kegiatan atau sifat pelayanan yang diberikan, maka rumah sakit menjadi "depot" segala macam penyakit, bahkan bisa pula merupakan sumber distribusi penyakit karena selalu dihuni, dipergunakan, dan dikunjungi oleh orang-orang yang rentan dan lemah terhadap penyakit. Di tempat ini dapat terjadi penularan baik secara langsung (cross infection), melalui kontaminasi benda-benda ataupun melalui serangga (vector borne infection) atau udara sehingga dapat mengancam kesehatan masyarakat umum. Limbah cair rumah sakit yang berupa senyawa-senyawa organik dan anorganik yang berasal dari laundry, dapur, ruang operasi, laboratorium, klinik dan lain-lain, ${ }^{(1)}$ apabila dibuang ke sungai akan menimbulkan dampak terhadap penduduk yang menggunakan air sungai untuk kebutuhan hidupnya.

Dalam penelitian ini akan diamati beberapa parameter pencemar air buangan rumah sakit, yang perlu diperhatikan yaitu BOD, COD, TSS dan fosfat. Mengacu pada Keputusan Gubernur Kepala Daerah Istimewa 
Pengaruh waktu ozonisasi terhadap penurunan kadar BOD, COD, TSS dan fosfat pada limbah cair Rumah Sakit.

Yogyakarta No. 65 tahun 1999 tentang Baku Mutu limbah cair bagi kegiatan pelayanan kesehatan di Propinsi Daerah Istimewa Yogyakarta adalah seperti pada Tabel 1 berikut.

Tabel 1. Kadar maksimum parameter air limbah cair pelayanan kesehatan sesuai Keputusan Gubernur DIY No. 65/1999. ${ }^{(2)}$

\begin{tabular}{|c|c|c|c|}
\hline No. & Senyawa & Baku Mutu & Limbah RS \\
\hline \hline 1 & BOD & $75 \mathrm{mg} / \mathrm{L}$ & $98,56 \mathrm{mg} / \mathrm{L}$ \\
\hline 2 & COD & $100 \mathrm{mg} / \mathrm{L}$ & $182,49 \mathrm{mg} / \mathrm{L}$ \\
\hline 3 & TSS & $100 \mathrm{mg} / \mathrm{L}$ & $255,32 \mathrm{mg} / \mathrm{L}$ \\
\hline 4 & Fosfat & $2,0 \mathrm{mg} / \mathrm{L}$ & $6,17 \mathrm{mg} / \mathrm{L}$ \\
\hline
\end{tabular}

Dampak yang ditimbulkan dari kandungan pencemar seperti BOD, COD, TSS dan fosfat yang tinggi dapat berbahaya sekaligus mematikan bagi ekosistem di perairan, apabila langsung dibuang ke badan air tanpa pengolahan terlebih dahulu. Masuknya padatan tersuspensi (TSS) ke dalam air dapat menimbulkan kekeruhan air, yang menyebabkan menurunnya laju fotosintesis fitoplankton dan tumbuhan air lainnya, sehingga produktivitas primer perairan menurun. Sedangkan kadar BOD dan COD yang tinggi dapat menyebabkan penurunan kandungan oksigen terlarut di perairan, yang dapat mengakibatkan kematian organisme akuatik. Sementara itu, dampak dari kandungan fosfat yang tinggi dapat mempercepat pertumbuhan mikroalgae pada perairan bebas. Dari beberapa jenis mikroalgae ada kelompok yang menghasilkan toksin bagi ikan dan biota air yang menutup permukaan air sehingga pancaran sinar matahari dan oksigen terlarut dalam perairan akan berkurang. ${ }^{(3)}$. Oleh karena pencemaran lingkungan mempunyai dampak yang sangat luas dan sangat merugikan manusia maka perlu dilakukan pengurangan pencemaran lingkungan atau apabila mungkin ditiadakan sama sekali. ${ }^{(4)}$

Untuk mengatasi permasalahan ini maka dibutuhkan suatu sistem pengolahan yang baik, agar diperoleh kualitas buangan yang memenuhi persyaratan baku mutu. Salah satu alternatif pengolahan yang tepat dan dapat diterapkan adalah dengan proses ozonisasi dengan perangkat generator ozon yang dapat menghasilkan $\left(\mathrm{O}_{3}\right)$ yang mempunyai kemampuan sebagai oksidator kuat, yang apabila dikombinasikan dengan adsorben kapur memungkinkan ozon dapat menguraikan berbagai senyawa organik diantaranya BOD, COD, TSS dan fosfat yang terkandung dalam limbah rumah sakit. Penurunan kadar BOD, COD, TSS dan fosfat yang dikombinasikan dengan penambahan kapur dengan pertimbangan bahwa penggunaan kapur dapat lebih mengefektifkan penurunan kadar BOD, COD dan TSS, karena disamping berfungsi sebagai koagulan juga sebagai pengontrol $\mathrm{pH}^{(5)}$

Fosfat berada dalam air limbah dalam bentuk organik, sebagai orthophosphate anorganic atau sebagai fosfat-fosfat kompleks. Fosfat komplek mewakili kira-kira separuh dari fosfat air limbah perkotaan dan berasal dari penggunaan bahan-bahan deterjen sintetis. Fosfat kompleks mengalami hidrolisa selama pengolahan biologis menjadi bentuk ortofosfat $\left(\mathrm{PO}_{4}^{3-}\right)$. Bila digunakan kapur maka akan terjadi reaksi sebagai berikut :

$$
\mathrm{Ca}(\mathrm{OH})_{2}+2 \mathrm{H}_{3} \mathrm{PO}_{4} \rightarrow \mathrm{Ca}_{3}\left(\mathrm{PO}_{4}\right)_{2} \downarrow+6 \mathrm{H}_{2} \mathrm{O}
$$

Prinsip kerja dari ozonizer adalah udara atau oksigen $\left(\mathrm{O}_{2}\right)$ dipompakan dengan kompresor udara, masuk melewati rongga yang berbentuk silindris, dimana rongga tersebut terbuat dari bahan stainless steel yang diselubungi tabung yang terbuat dari kaca, tabung kaca disebut sebagai bahan dielektrikum. Bila antara permukaan tabung yang luar dengan tabung yang di dalam diberi beda tegangan yang relatif tinggi $( \pm 24 \mathrm{kV})$ maka akan terjadi lucutan listrik yang relatif merata. Sehingga pada ruang antara tabung terjadi awan elektron. Bila dalam awan elektron ada gas oksigen maka akan terbentuk gas ozon seperti pada reaksi sebagai berikut.

$$
\begin{aligned}
& \mathrm{e}^{*}+\mathrm{O}_{2} \rightarrow \mathrm{O}^{*}+\mathrm{O}^{*} \\
& \mathrm{O}^{*}+\mathrm{O}_{2} \rightarrow \mathrm{O}_{3}
\end{aligned}
$$

$\mathrm{O}^{*}$ bersifat radikal sehingga apabila bertumbukan dengan air akan membentuk ion hidroksil $(\mathrm{OH})$ yang kemudian pada gilirannya akan berperan dalam merombak ikatan-ikatan dari persenyawaan kimia, baik organik maupun 
anorganik yang terdapat dalam limbah, sehingga mikroorganisme akan mengalami kekurangan bahan atau nutrisi yang akan diurai, dengan demikian akan mengurangi jumlah oksigen yang terkandung di dalam limbah tersebut. ${ }^{(6)}$

Dengan demikian diharapkan pemakaian teknologi plasma yang dikombinasikan dengan penambahan kapur dapat menurunkan kadar BOD, COD, TSS dan fosfat dalam limbah cair rumah sakit.

\section{TATA KERJA}

\section{Bahan}

Bahan yang dijadikan sampel penelitian adalah natrium hidrogen fosfat dihidrat $\left(\mathrm{Na}_{2} \mathrm{HPO}_{4}{ }_{2} 2 \mathrm{H}_{2} \mathrm{O}\right.$ Merck p.a), kalium iodida (KI Merck p.a), kalium dihidrogen fosfat $\left(\mathrm{KH}_{2} \mathrm{PO}_{4}\right.$ Merck p.a), $\mathrm{H}_{2} \mathrm{SO}_{4}$ pekat, kapur, aquades, dan buangan limbah cair RSUD Kota Samarinda, Kalimantan Timur.

\section{Alat}

pH meter, timbangan, alat penggerus, ozonizer 100 watt dan alat-alat gelas.

\section{Cara Kerja}

1. Air limbah sebanyak $1000 \mathrm{ml}$ dimasukkan dalam botol gelap, kemudian ditambahkan kapur ukuran 100 mesh yang divariasikan dari $0,9 \% ; 1,0 \% ; 1,1 \% ; 1,2 \%$ dan 1,3\%. Kemudian dilakukan proses ozonisasi selama 20 menit, dilakukan pengulangan tiga kali dan kemudian dianalisis kadar BOD, COD, TSS dan fosfatnya, maka akan diperoleh kadar penambahan kapur yang optimal.

2. Air limbah sebanyak $1000 \mathrm{ml}$ dimasukkan dalam botol gelap, kemudian ditambahkan kapur dengan kadar yang optimal dari percobaan no. (1), kemudian dilakukan proses ozonisasi dengan waktu yang divariasi dari 5, 10, 20, 30 dan 40 menit. Perlakuan ini dilakukan pengulangan tiga kali dan kemudian dianalisis kadar BOD, COD, TSS dan fosfat, sehingga diperoleh waktu ozonisasi yang optimal.

\section{HASIL DAN PEMBAHASAN}

Dari penelitian dengan parameter penambahan kapur dapat dilihat pada Gambar 1 berikut ini.

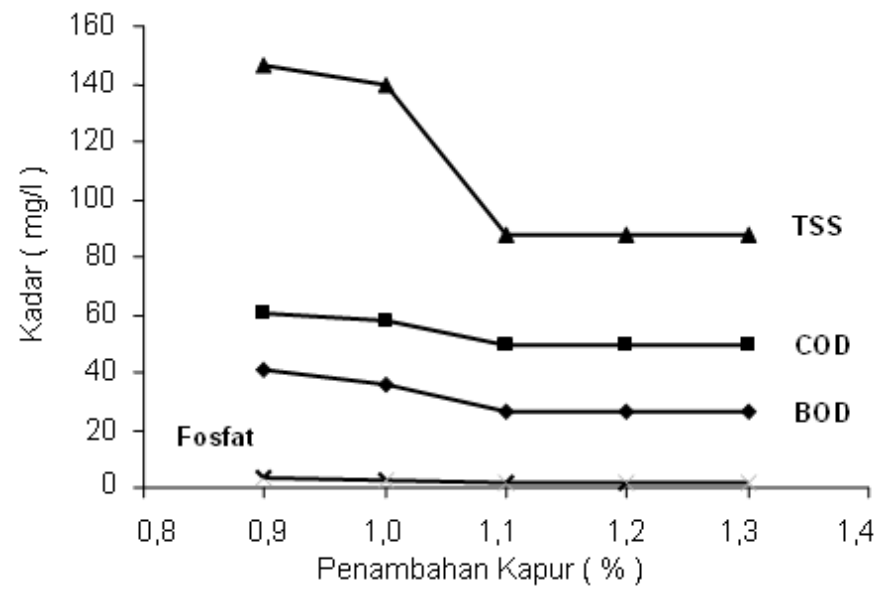

Gambar 1. Pengaruh penambahan kapur (\%) terhadap kadar BOD, COD, TSS dan fosfat.

Pada tulisan awal sudah dijelaskan, bahwa dengan menggunakan ozon sebagai oksidator maka akan menambah jumlah senyawa $\mathrm{OH}^{-}$dan radikal $\mathrm{O}^{*}$ yang terbentuk dalam larutan. Apalagi bila ditambahkan kapur, sebagai pengatur $\mathrm{pH}$ larutan, maka jumlah senyawa radikal $\mathrm{OH}^{-}$semakin banyak. Sehingga di dalam larutan limbah terdapat tiga senyawa oksidator yang terjadi secara bersama-sama yaitu radikal $\mathrm{OH}^{-}$, radikal $\mathrm{O}^{*}$ dan ozon sendiri. Ketiga senyawa ini sangat efektif untuk mendegradasi BOD, COD dan fosfat. 
Pada Gambar 1 dapat dilihat bahwa semakin besar penambahan kapur maka kadar BOD, COD dan fosfat semakin turun. Hal ini karena sifat yang sangat reaktif dari senyawa radikal $\mathrm{OH}^{-}$, radikal $\mathrm{O}^{*}$ dan ozon, seperti yang ditunjukkan pada Tabel 2 berikut ini. ${ }^{(6)}$

Tabel 2. Potensial oksidasi berbagai senyawa.

\begin{tabular}{|l|c|c|c|}
\hline \multicolumn{1}{|c|}{ Unsur } & Pot Oksidasi (volt) & Unsur & Pot Oksidasi (volt) \\
\hline \hline Fluorine $(\mathrm{F})$ & 2,87 & $\mathrm{H}_{2} \mathrm{O}_{2}$ & 1,78 \\
\hline Radikal $\left(\mathrm{OH}^{-}\right)$ & 2,86 & $\mathrm{Cl}$ & 1,36 \\
\hline Radikal $\left(\mathrm{O}^{*}\right)$ & 2,42 & $\mathrm{ClO}_{2}$ & 1,27 \\
\hline Ozon $\left(\mathrm{O}_{3}\right)$ & 2,07 & $\mathrm{O}_{2}$ & 1,23 \\
\hline
\end{tabular}

Adapun reaksi yang dimungkinkan dapat terjadi adalah sebagai berikut ${ }^{(7)}$ :

$$
\begin{aligned}
& \mathrm{C}_{n} \mathrm{H}_{\mathrm{a}} \mathrm{O}_{b} \mathrm{~N}_{c}+\left(n+\frac{a}{2}-b-\frac{3 c}{2}\right) \mathrm{O}^{*} \rightarrow \mathrm{CO}_{2}+\left(\frac{a}{2}-\frac{3 c}{2}\right) \mathrm{H}_{2} \mathrm{O}+\mathrm{c} \mathrm{NH}_{3}(4) \\
& \frac{1}{a} \mathrm{C}_{\mathrm{a}} \mathrm{H}_{\mathrm{b}} \mathrm{O}_{\mathrm{c}}+\left(\frac{n}{2}+\frac{b}{2 a n}-\frac{c}{a n}\right) \mathrm{O}^{*} \rightarrow \mathrm{CO}_{2}+\left(\frac{b}{2 a}\right) \mathrm{H}_{2} \mathrm{O} \text { 5) }
\end{aligned}
$$

Sedangkan dengan penambahan kapur maka akan mengubah kestabilan koloid sehingga mempercepat terjadinya endapan flok ${ }^{(5)}$, seperti pada reaksi berikut :

$$
\begin{aligned}
& \mathrm{CaO} \rightarrow \mathrm{CaO}_{\text {flok }} \\
& \mathrm{CaO}_{\text {flok }}+(\text { Organik }) \rightarrow \mathrm{CaO}----(\text { Organik })_{\text {flok }} \downarrow
\end{aligned}
$$

Dengan adanya reaksi-reaksi (1), (4), (5), (6), dan (7) ini maka kadar BOD, COD, TSS dan fosfat dalam limbah turun secara signifikan. Tetapi pada penambahan kapur $1,1 \%$ (berat) sudah terjadi penurunan yang maksimal, karena setelah titik tersebut penambahan kapur relatif tidak mempengaruhi penurunan kadar BOD, COD, TSS dan fosfat dalam limbah. Hal ini dimungkinkan karena larutan limbah sudah jenuh, sehingga penambahan kapur tidak mempengaruhi kadar ke-empat pencemar. Oleh karena itu konsentrasi kapur 1,1\% digunakan untuk proses berikutnya yaitu mempelajari parameter waktu ozonisasi. Rentang waktu ozonisasi yang dilakukan adalah 5, 10, 20, 30 dan 40 menit. Pemilihan rentang waktu ini berdasarkan percobaan awal, bahwa perlakuan di bawah 10 menit belum memberikan hasil yang diharapkan. Pengamatan parameter waktu ozonisasi ini dapat dilihat pada Gambar 2.

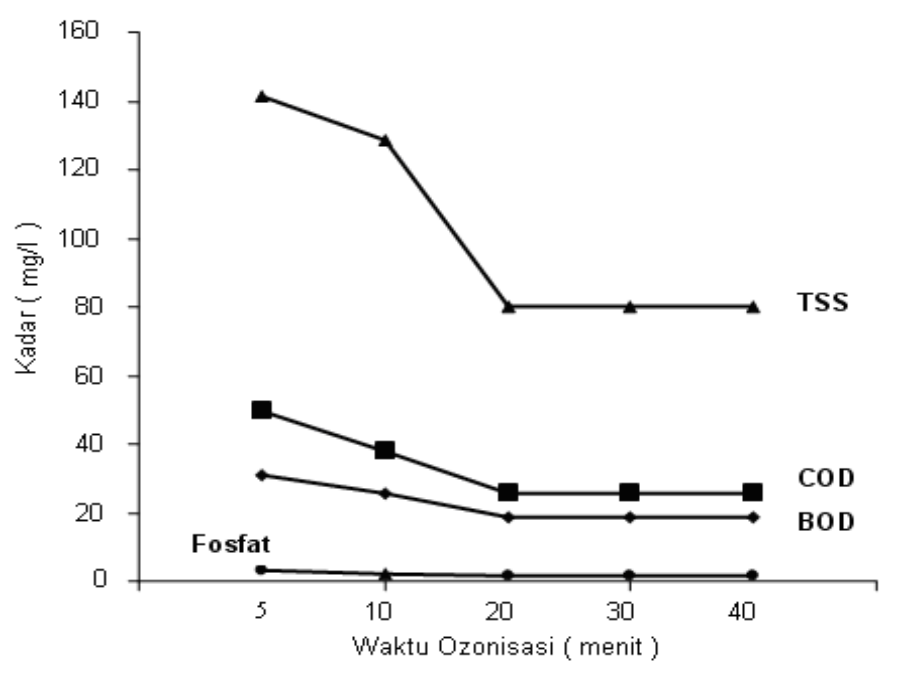

Gambar 2. Pengaruh waktu ozonisasi (menit) terhadap kadar BOD, COD, TSS dan fosfat. 
Pada Gambar 2 dapat dilihat bahwa semakin lama waktu ozonisasi dilakukan maka semakin turun kadar BOD, COD, TSS dan fosfat dalam limbah. Hal ini dapat dimengerti bahwa dengan menambah waktu ozonisasi maka akan menambah jumlah senyawa radikal $\mathrm{OH}^{-}$, radikal $\mathrm{O}^{*}$ dan ozon dalam limbah. Sehingga ketiga senyawa inilah yang secara bersama-sama akan mengoksidasi BOD, COD dan fosfat seperti reaksi yang telah disebutkan di muka. Sedangkan dengan semakin banyak ozon diberikan ke dalam larutan limbah maka akan semakin banyak flok yang terbentuk, sehingga flok-flok ini akan menyerap koloid-koloid dalam limbah. Hal ini menyebabkan kadar TSS dalam limbah turun.

Penurunan kadar BOD, COD, TSS dan fosfat secara signifikan terjadi dari waktu ozonisasi 5 menit hingga 20 menit. Setelah itu penambahan waktu ozonisasi relatif tidak mempengaruhi penurunan kadar BOD, COD, TSS dan fosfat. Hal ini karena reaksinya sudah jenuh dan ozon yang berlebihan pada umumnya akan berubah kembali menjadi oksigen. ${ }^{(6)}$ Oleh karena itu waktu ozonisasi yang optimal adalah 20 menit. Dengan kondisi operasi ini kadar ke-empat pencemar sudah memenuhi baku mutu yang sudah ditentukan.

\section{KESIMPULAN} bahwa

Berdasarkan hasil penelitian yang telah dikemukakan dimuka, maka dapat diambil suatu kesimpulan

1. Semakin besar kadar kapur ditambahkan ke dalam limbah maka semakin turun kadar BOD, COD, TSS dan fosfat. Kadar kapur yang optimum adalah $1,1 \%$.

2. Semakin besar waktu ozonisasi dikenakan dalam limbah maka semakin turun kadar BOD, COD, TSS dan fosfat. Waktu ozonisasi yang optimum adalah 20 menit.

3. Dengan kondisi operasi yang optimum tersebut diperoleh kadar BOD $=18,88 \mathrm{mg} / \mathrm{L}, \mathrm{COD}=25,68 \mathrm{mg} / \mathrm{L}$, $\mathrm{TSS}=80,0 \mathrm{mg} / \mathrm{L}$ dan fosfat $=1,52 \mathrm{mg} / \mathrm{L}$. Kadar tersebut sudah memenuhi baku mutu yang ditetapkan yaitu untuk BOD $=75 \mathrm{mg} / \mathrm{L}, \mathrm{COD}=100 \mathrm{mg} / \mathrm{L}, \mathrm{TSS}=100 \mathrm{mg} / \mathrm{L}$ dan fosfat $=2,0 \mathrm{mg} / \mathrm{L}$.

\section{Ucapan Terima Kasih}

Dengan selesainya penelitian ini disampaikan ucapan terima kasih yang sebesar-besarnya kepada Sdr. Lisnawati, mahasiswa tugas akhir STTL Yogyakarta dan rekan-rekan teknisi Lab. Plasma atas bantuannya, dari awal hingga selesainya penelitian ini.

\section{DAFTAR PUSTAKA}

1. DERAP BETHESDA, Edisi Kedua, Desember 1997.

2. KEPUTUSAN GUBERNUR KEPALA DAERAH ISTIMEWA YOGYAKARTA No. 65 tahun 1999 tentang Baku Mutu limbah cair bagi kegiatan pelayanan kesehatan di Propinsi Daerah Istimewa Yogyakarta, 1999.

3. SOEMIRAT, J.S, Kesehatan Lingkungan, Gajah Mada University Press, Yogyakarta, 1994.

4. WISNU ARYA WARDANA, Dampak Pencemaran Lingkungan Hidup, Penerbit Andi Yogyakarta, Yogyakarta, 2001.

5. TJOKROKUSUMO, Pengantar Engineering Lingkungan, Sekolah Tinggi Teknik Lingkungan "Yayasan Lingkungan Hidup" Yogyakarta, 1998

6. KRIS TRI BASUKI, WIDDI USADA, AGUS PURWADI, ISYUNIARTO, Rancang Bangun Ozonizer Jinjing dan Manfaatnya Untuk Netralisasi Limbah Cair Industri dan Paska Panen, Seminar Nasional Teknologi Proses Kimia VII, Universitas Indonesia, Jakarta, 2005

7. ISYUNIARTO, Aplikasi ozonizer pada industri, kesehatan dan lingkungan, Laporan Intern, Disajikan dalam Presentasi dan Sosialisasi Aplikasi ozonizer pada industri, kesehatan dan lingkungan, PMBIBATAN, Serpong, 7 November 2005 